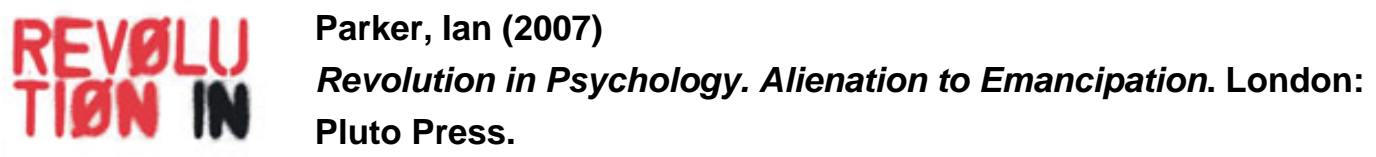

ASenation to Emanciseation
lan Parker

ISBN: 9780745325354

\title{
Simone Belli
}

\section{Universitat Autònoma de Barcelona}

simone.belli@uab.cat

Cuando se trata el tema de la "Revolución" en las Ciencias Sociales no se puede olvidar una figura tan importante como la de Toni Negri. El mismo Negri define esta obra como "un acercamiento metodológico radical y abierto al cambio social, con una clara perspectiva anti-capitalista, anti-racista y de parte de las políticas feministas". Esto es, sin duda, lo que nos propone lan Parker con su nuevo libro "Revolution in Psychology". De forma particular, Parker nos advierte de los peligros de la corriente principal de la psicología y de sus consecuencias en la sociedad. Este libro ofrece al lector una visión alternativa, nos propone prácticas políticas "subversivas" para combatir esta manera de hacer psicología que se ha instalado en las universidades y que se aísla completamente de los cambios constantes y continuos, prerrogativa fundamental, de las Ciencias Sociales.

Uno de los primeros objetivos del autor es de proponer algunas prácticas subversivas en la psicología positiva que, en los últimos años, está consiguiendo tomar algunos espacios dentro de los medios de comunicación, y lo que es más preocupante, en las revistas científicas del sector. Hablaríamos de una constante "psicologización" de la vida cotidiana producida por el capitalismo. Según el autor, esta psicologización es esencial y necesaria para el capitalismo ya que la Psicología se está dirigiendo a una dirección: conseguir la felicidad para "el individuo". El producto de la sociedad capitalista es la psicología positiva que busca la felicidad del individuo. El individuo es el gran protagonista de los últimos estudios psicológicos, su felicidad es el objetivo primordial. Sin este principio la Psicología contemporánea parece no sentirse "satisfecha".

La tesis principal de este libro es que las prácticas psicológicas modernas constituyen el problema, más que ser las soluciones. En la mayoría de los casos, la perspectiva critica, queda como una ciencia de minorías, que por militancia o por ideales se refugian en ella. Sin duda alguna este es un razonamiento equivocado porque la "Psicología Social Crítica", y más concretamente la "Psicología Critica", forman parte de la evolución constante en las Ciencias Sociales. Por este motivo podemos afirmar que lo que hace 30 años era crítico, hoy lo podemos encontrar como corriente principal de la psicología. Por ejemplo, el cognitivismo se afirmó como perspectiva crítica en relación al conductismo a partir de los años sesenta. Posteriormente fue la perspectiva construccionista la que interpretó este rol, hasta llegar a la perspectiva post-construccionista y deconstruccionista. Es por este motivo que la verdadera revolución a veces es advertir tales cambios, comprender la importancia de la perspectiva 
crítica en cada aspecto de las Ciencias Sociales. Es una revolución constante y necesaria, siempre hay que esperar esta revolución. Al igual que las revoluciones, para que haya un cambio, una inflexión, tiene que haber una ruptura con los dogmas pasados y los prejuicios pasados. En este libro se tienta a todos los aspectos de la psicología con esta idea de revolución. Porque los términos revolución, conflicto y lucha tienen el mismo sentido, producen el mismo efecto. Esta revolución, según el autor, tiene que ser continua, constante y sobre todo activa. Entonces el acto de reflexionar cotidianamente sobre lo que estamos haciendo, nuestras prácticas cotidianas en el trabajo científico, profesional, nos ayuda a evolucionar.

El activismo de Parker en el ámbito propio de la Psicología no se limita simplemente a la teoría, él mismo es miembro y protagonista del PPR (Psychology Politics Resistance), un movimiento para la democratización de la psicología y de la psiquiatría. La psicología está tratada como parte del problema de la sociedad capitalista, individualizando y esencializando los procesos sociales, en lugar de concebir los problemas como procesos sociales. Esta manera de hacer y de entender la psicología está destinada al fracaso, según el autor. Es por este motivo que el segundo título del libro es "Alienation to Emancipation". De hecho, este proceso de individualización de la actual psicología produce uno de los aspectos más destructivos de la alienación, que es la separación en la gente de los sentimientos de miseria y rabia, hasta a la propia opresión y un "pensamiento negativo" general y constante.

Desde el punto de vista de una Psicólogo Social, estos cambios en el interior de la sociedad no pueden pasar inadvertidos, tienen que estar presentes en su visión personal y profesional de la sociedad. Nunca tienen que ser un misterio, ni procesos obscuros para un Psicólogo Social.

Interesante y sobre todo útil es la última parte del libro donde el autor nos propone algunos trabajos importantes dentro de esta perspectiva crítica en todas las áreas de la Psicología y de las Ciencias Sociales.

Ian Parker no es nuevo en estas prácticas radicales, su pensamiento crítico es conocido dentro de la Psicología Social. Se puede afirmar ciertamente que es una de las figuras más importantes dentro de la Psicología Critica. Este libro, como nos dice el mismo Parker, "es para aquellas personas que quieren cambiar el mundo, probando de encontrar sentido a la propia manera de "hacer" psicología y de hacer conexiones entre psicología y políticas radicales. Encontrar directamente la propia psicología en la actividad política."

\section{Formato de citación}

Belli, Simone (2007). Reseña de I.Parker "Revolution in Psychology". Athenea Digital, 12, 366-368. Disponible en http://psicologiasocial.uab.es/athenea/index.php/atheneaDigital/article/view/432 


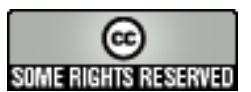

Este texto está protegido por una licencia Creative Commons.

Usted es libre de copiar, distribuir y comunicar públicamente la obra bajo las siguientes condiciones:

Reconocimiento: Debe reconocer y citar al autor original.

No comercial. No puede utilizar esta obra para fines comerciales.

Sin obras derivadas. No se puede alterar, transformar, o generar una obra derivada a partir de esta obra.

\section{$\underline{\text { Resumen de licencia }}$}

$\underline{\text { Texto completo de la licencia }}$ 